\title{
ERGONOMIC AUDIT - A NEW MANAGEMENT FUNCTION
}

\author{
Aurel MANOLESCU ${ }^{a}$, Irinel MARIN ${ }^{b}$, Monica TRICULESCU ${ }^{c^{*}}$ \\ ${ }^{a},{ }^{b},{ }^{c}$ Bucharest University of Economic Studies, Romania
}

\begin{abstract}
Ergonomic audit is approached from the perspective of general trends in organizational and managerial development as well as the development and maturation of ergonomics, and as widely recognized theoretical and practical constructions. Beyond the terminological dispute, which can be explained in part, or the existence of difficulties and barriers, often invoked, it is presented the permanent evolution of ergonomic audit as a result of needs for conceptual and methodological consolidation in continuous change. In particular, are mentioned the scientific grounds and reasons for the development of ergonomic audit, its characteristics and the movement of objectives towards risk identification, certification of entities or verification of compliance with certain pre-established ergonomic criteria or associated standards. At the same time, the relatively recent mutations of the audit objectives from the traditional ones to the management issues are signaled, as well as the transition from the evaluation of the quantitative dimensions to the estimation of the qualitative aspects, including those of ergonomic nature. Consequently, ergonomic audit must be increasingly approached as a managerial tool, thus becoming a new function of ergonomic management, which requires that this modern concept, necessary and particularly useful, be institutionalized, understood, assumed and properly promoted.
\end{abstract}

KEYWORDS: ergonomic audit; ergonomic standards; management function.

\section{GENERAL CONSIDERATIONS}

From the perspective of some general tendencies regarding the organizational and managerial development or the development and maturation of ergonomics, the appearance of new paradigms, as well as of some theoretical and practical constructions of wide recognition, a special place returns, by importance, size and implications of ergonomic audit as a new management function.

The emergence and development of ergonomic audit are objectively determined, including, by contemporary socio-technical trends as well as by the profound transformations that condition the characteristics of modern competitive and sustainable organizations.

The need to develop ergonomic audit also has many other scientific grounds or reasons to consider, as its characteristics make it easier to explain the contribution of potential values of ergonomics.

In order to reach a better understanding of the importance of the role and content of modern audit, in general, and ergonomic audit in particular, it is necessary and particularly useful to understand the historical evolution of audit in general, a process that can form a useful basis or an important premise for the analysis and interpretation of significant changes that have influenced the objectives, values, techniques and values of the audit.

Being, however, a very broad framework of the historical incursion, we limit ourselves to only a few significant aspects:

\footnotetext{
* Corresponding author. E-mail address: monica.triculescu@man.ase.ro
} 
- The appearance and development of the audit is a process whose characteristics are determined, in time and space, by a multitude of objective and subjective factors, which condition the development of organizations, in general and competitive ones in particular.

- The evolution of audit concerns has gone through several stages or periods, relatively distinct, their specificity being determined, first of all, by the way in which advanced capital was protected and used, the owners themselves trying to verify the correctness of activities and existing information.

Therefore, the audit was born and evolved as a result of constantly changing needs imposed by the development of organizations, business as a whole and competition, when survival on the market depends, almost exclusively, on the protection and full use of their own. capital.

In other words, the audit function was strongly marked by its economic, financial, accounting or technical origins, connotations that are still preserved in the collective memory.

\section{ERGONOMIC AUDIT}

In the practice of organizations, the essential condition for competitive and sustainable competitive success proves to be, more and more, the realization of an honest, accurate and objective evaluation of the activities carried out and implicitly of the resources used.

Consequently, all the functions within an organization, all the activities and behaviors associated with them, including those of an ergonomic nature, must be periodically, audited and evaluated.

In this context, the appearance and development of ergonomic audit represents both the consequence of the historical evolution of audit in general and of ergonomics in particular, as well as the result of diversification tendencies of the theory and practice of classical or traditional audit. The appearance and development of the ergonomic audit, constitutes, at the same time, the official recognition of the new requirements and exigencies regarding the fullest and superior capitalization of the human potential, in general and of the ergonomics in particular.

Also, as organizations have developed and the "business world" faces new challenges and many difficulties, audit objectives have shifted their focus from detecting fraud or preventing unwanted acts to identifying risks, certifying entities (processes, products, systems) or their performance so that, at present, the emphasis is on verifying compliance with certain pre-established criteria or specific standards.

In recent decades, other changes can be seen, such as the shift in an objective and natural way from the audit of resource management to management issues, as well as the transition from assessing quantitative dimensions, mainly economic and technical, to estimating qualitative aspects of activities. or organizational issues, including those of an ergonomic nature.

From this perspective, the audit is more and more viewed or approached as a managerial tool, which allows, using the most appropriate techniques, obtaining a more accurate picture of the organizational reality.

Derived from the monitoring of the results of ergonomic activities or interventions, in real time, the ergonomic audit has constantly evolved, becoming a function of ergonomic management, thus helping. management and stakeholders (stakeholders) because making decisions based on relevant or accurate information is beneficial in the long run.

Consequently, the elaboration of managerial decisions regarding ergonomic programs requires knowledge of the implementation stage of previous actions in the field of ergonomics, an opinion expressed by other authors (Drury, 2006) who emphasize that the purpose of ergonomic audit is to measure previous major problems. without waiting for some rare events to evaluate an ergonomic audit program.

However, beyond the terminological dispute that can be explained in part by the fact that like other scientific fields, the ergonomic audit is not born suddenly and fully constituted, there are, objectively some, differences of opinion or different approaches regarding to the circumscription of 
the objectives of the ergonomic audit, as well as to its real significance or the delimitation of its scope, aspects widely presented in the specialized literature. (Drury, 2006)

In this context, we mention only the fact that in the conditions in which the audit represents the testing and verification of the way in which the policies and practices are accepted (Carson and Clarson, 1977), the phrase "accepted policies and practices" can be extended in the field of ergonomics. (Drury, 2006)

In the field of ergonomics, auditing takes the form of measuring or evaluating the characteristics of a sample of jobs to determine to what extent the ergonomic requirements or criteria, the specific relationships of human-machine systems or the ergonomic quality of socio-technical systems are respected or satisfied (C.G. Drury, 2006).

In other words, ergonomic audit moves from workplace activities (microergonomics) to sociotechnical systems including the organizational system (organizational ergonomics) to obtain conclusions, make recommendations or propose valid solutions to meet ergonomic requirements at the level of system.

Also, for a more complete understanding of the problems, aspects or ergonomic requirements, the data and information from the ergonomic audit process can be supplemented or completed and combined with other data in the archive.

Although, according to the literature, ergonomic audit has a significant potential and many associated benefits, in terms of promoting and implementing ergonomic audit still persist, some difficulties or barriers continue to arise, for reasons frequently invoked but inherent in any beginning such as:

- Organizations do not have a strong enough perception of the importance and role of ergonomic audit;

- "Ergonomic audit" is not always associated with a positive function or organizational efficiency;

- Insufficient media coverage of the term "ergonomic audit", in relation to the maturation process of ergonomics;

- The use, unfortunately, even by specialists in the field, of the terms "ergonomic audit" or "labor inspection” as synonyms or equivalents, having the same meaning;

- Insufficient and inadequate or less convincing promotion of "ergonomic audit";

- Most practitioners do not benefit from formal education in the field of ergonomic audit nor from specific continuing education.

Despite all the barriers, confusions or dysfunctions that are still maintained in the practice of ergonomic audit, it has always been redefined over time, which leads to an adequate evolution with objectives increasingly understood, promoted and implemented.

Consequently, in the specialized literature there are or are confronted numerous opinions or different forms according to which the ergonomic audit has the following characteristics:

- Represents the evaluation and verification of the way in which the policies and practices in the field of ergonomics have been consistently or permanently observed;

- It is a systematic approach of professional evaluation of the degree of implementation or integration of ergonomics in the strategy of an organization;

- Represents a set of research or examination policies, procedures, systems and practices regarding the evaluation of ergonomic management functions;

- It is an independent and objective activity that gives organizations the promotion and implementation of ergonomic requirements and associated standards;

- Expresses the estimation of the conformity of the organizational structure of a socio-technical system with the requirements, criteria and ergonomic standards;

- It is a particular way of pragmatic knowledge of organizational realities from the perspective of ergonomics requirements;

- It is an approach that highlights the relationship between current practices and ergonomic requirements; 
- It is a systematic process of monitoring, obtaining and evaluating data and information on activities in the field of ergonomics that ensures management and stakeholders that those activities were carried out according to ergonomic requirements and standards;

- Represents the process of assessing the practices in the field of ergonomics in order to certify, certify or validate compliance with specific requirements and standards;

- It is a system of consulting, analytical assessment and expertise, a finding and a professional and independent assessment of the ergonomic capacity of a modern and competitive organization.

Going through and analyzing the different characteristics of ergonomic audit, beyond the scientific aspect, it can be seen that some differences hide certain differences of opinion regarding the role, content and objectives of ergonomic audit, as a managerial function. However, it can be appreciated that the many features presented do not contain contradictory elements but complement each other, each contributing to the circumscription of the content of the ergonomic audit.

Detaching itself from the human resources audit, the ergonomic audit differentiated and became autonomous, remaining its problems or objectives of analysis and evaluation and consequently specialized.

Starting from an already outlined field, that of classical, traditional audit, borrowing from it, not without difficulty, some concepts or methods of research and evaluation, even the language of expression or some analogies, ergonomic audit specifies its object of study and it draws or delimits its own border, so that organizational realities are approached, analyzed and evaluated from the perspective of ergonomics requirements and compliance with specific or associated standards.

In relation to the scope, levels of coverage or levels of approach, the boundaries of ergonomic audit may be wider or narrower, including or excluding, as appropriate, certain aspects that make up or define the specific nature of ergonomic audit.

Although all types of auditing have the same scientific basis, and a common philosophy, ergonomic auditing is an extension of what organizational aspects mean because it promotes a more comprehensive and integratively structured approach that emphasizes the importance of organizational context and its synergy.

The finality in ergonomic audit consists in attesting and validating the results obtained by organizations from the perspective of integrating ergonomics in organizational activities as well as in terms of compliance of ergonomics actions or interventions with the requirements of ergonomics and associated standards.

From this perspective, the degree of compliance, ergonomic actions or interventions, can affect the degree of exposure of an organization, in the event of a lawsuit, because non-compliance with specific legislation or ergonomic standards can often adversely affect, including disputes involving based on non-compliance with the requirements of ergonomics (Ergonomic Justice).

Consequently, the issue of ergonomics as the basis of justice has begun to make its presence felt or to be addressed more and more, due to complaints, grievances or claims from customers or end users, in connection with non-compliance with ergonomic requirements in designing work environments in general and products in particular.

Ergonomic audit is also an interdisciplinary field, relatively difficult, of a particular complexity due, firstly, to the fact that ergonomics is a product of interdisciplinarity and therefore must be studied as such, and secondly, not in all situations the ergonomic requirements or the associated standards are universally valid and applicable.

All these aspects determine an increase in the importance and role of ergonomic audit, until its professionalization and institutionalization, not only as a powerful tool for detecting or identification the main organizational risks, but also as an indispensable managerial tool and not 
least as a new managerial function that allows the systemic and systematic understanding of both organizational realities and human behavior from the perspective of ergonomic requirements.

Consequently, ergonomic audit must be a strategic priority for modern organizations because, as a managerial function, through the activities they carry out, it adds value which has a positive and particularly favorable influence on organizational effectiveness as a whole. (Dul, 2003, 2007, 2009; Dul \& Neumann, 2009)

The need to develop a managerial perspective, to cultivate or maintain a new managerial function is also determined by numerous organizational and managerial factors, objective and subjective, widely presented in the literature. (Manolescu, 2003, 2015)

From this perspective, the need was felt to approach the ergonomic audit from a much broader, more comprehensive and more integrative (holistic) perspective, which forces or challenges the management to reconsider many of the current ways of design and organizational and managerial development.

In these conditions, the ergonomic audit is a current trend, fully justified and of a special importance, as the theoretical and practical approaches in this field of activity, in our country, are in an incipient phase. Therefore, ergonomic audit is developing and consolidating beyond the audit of human resources management, trying to extend its interdisciplinary and holistic approach.

Such an integrative approach in the field of ergonomic audit is not only a challenge, but also a problem of reflection because it has in its objective determination, both some aspects related to expertise in the field of human factors and ergonomics, and aspects related to authentic scientific knowledge in the field of organization management or human resources management and not least of ergonomic management.

\section{CONCLUSIONS}

Considering the aspects or considerations briefly presented, but treated extensively in the literature (Karwowski, 2006), we emphasize that they highlight the fact that the concerns in the field of ergonomic audit are at such a stage that it is necessary not only to amplify and boost them, but also a notable approach leading to the development and conceptual and methodological consolidation of ergonomic audit.

Therefore, being a modern, necessary and particularly useful concept, ergonomic audit, as a new managerial function, must be understood, assumed and promoted properly and constantly, especially by modern organizations to succeed, become competitive and have a sustainable future

\section{REFERENCES}

Drury, G., C. (2006). Ergonomics/Human Factors Audits. In: International Encyclopedia of Ergonomics and Human Factors, Vol. 2, Second Edition. London, England: Taylor \& Francis Group, pp. 1106-1132.

Drury, G., C. (2006). Human factors and ergonomics audits. În: Handbook of human factors and ergonomics, Chapter 4, Third Edition. London, England: John Wiley \& Sons, Inc. pp. 11061111.

Dul, J. (2003). Ergonomics in management. Paper presented at The Triennial Congress of the International Ergonomics Association. Seoul, South-Korea. 
Dul, J. (2007). The Strategic Business Value of Ergonomics. In: R. Pikaar, E. Koningsveld \& P. Settels (Ed), Meeting Diversity in Ergonomics. Paper presented at the 16th Triennial World Congress of the International Ergonomics Association, Maastricht, 2006. Maastricht, The Netherlands: Elsevier Science.

Dul, J. (2009). Business ergonomics beyond health and safety: work environments for employee productivity, creativity and innovation. In: Contemporary Ergonomics. London, England: Taylor \& Francis Group.

Dul, J., Neumann, P., W. (2009). Ergonomics contributions to company strategies. Applied Ergonomics, 40, 745-752.

Karwowski, W. (2006). International Encyclopedia of Ergonomics and Human Factors, Vol. 1, 2, 3, Second Edition. London, England: Taylor \& Francis Group.

Manolescu, A. (2003). Viitorul managementului resurselor Umane şi ergonomia. În: A. Manolescu (Ed), Managementul resurselor umane, ediţia a patra. Bucureşti: Editura Economică.

Manolescu, A. (2015). Ergonomie organizationala. Bucureşti: Editura Economică. 